\title{
El hilo sutil de la rememoración. Felicidad y redención histórica en la obra de Walter Benjamin
}

\author{
The Thin Thread of Remembrance. Happiness and \\ Historical Redemption in Walter Benjamin's Work
}

\author{
SANDRA VIVIANA PALERMO \\ Università de Pavia
}

\begin{abstract}
RESUMEN. El texto presenta un análisis de la estructura del tiempo mesiánico que Benjamin intenta pensar desde el punto de vista de su indisoluble conexión con los conceptos de felicidad y redención. El recorrido conceptual va desde los escritos de juventud, en los que la constelación felicidad-redención adquiere una fisionomía definida - conjugándose con una crítica elegante y puntual de la modernidad-, a las tesis Sobre el concepto de historia, en las cuales tal constelación se entrelaza con la figura del Eingedenken, que determina un desplazamiento conceptual importante en el horizonte teórico del autor, representando además la especificidad y la riqueza de su reflexión sobre el tiempo y la historia.
\end{abstract}

Palabras clave: Mesianismo, redención histórica, felicidad.
ABSTRACT. This paper presents an analysis of the structure of the Messianic time that Benjamin tries to think from the point of view of its inextricable connection to the concepts of happiness and redemption. The conceptual route goes from the early writings, in which the constellation happiness-redemption acquires a definite physiognomy — combining with an elegant and specific critique of modernity — to the thesis Über den Begriff der Geschichte, in which this constellation is intertwined with the figure of Eingedenken, which determines an important conceptual shift in the theoretical horizon of the author, also representing the specificity and richness of his reflections on time and history.

Key words: Messianism, Historical redemption, Happiness.

\section{Hendiduras del tiempo: felicidad y redención}

El 16 de marzo de 1937, comentando su texto sobre Eduard Fuchs, Max Horkheimer le escribe a Benjamin: «La afirmación de la no definitividad de la historia es idealista, si en ella no queda incluida la de la definitividad. La injusticia pasada acaeció y está definitivamente concluida. Los muertos están verdaderamente muertos... Si se pretende tomar en serio la afirmación de la no-definitividad hay que creer en el juicio universal. Acaso respecto de la no-definitividad exista una diferencia entre lo positivo y lo negativo, es de- 
cir, la injusticia, los horrores, los dolores del pasado son irreparables. La justicia realizada, las alegrías, las obras entran en relación con el tiempo de manera distinta, pues su carácter positivo queda ampliamente negado por la caducidad» ${ }^{1}$. Benjamin incluye esta carta entre los materiales preparatorios para la obra sobre los Pasajes de París, añadiendo el siguiente comentario: «el correctivo de estos razonamientos está en la consideración de que la historia no sólo es una ciencia, sino también, y no menos, una forma de la rememoración [Eingedenken]. Lo que la ciencia ha establecido puede ser modificado por la rememoración. La rememoración puede transformar lo incumplido (la felicidad) en un cumplido y lo cumplido (el dolor) en un incumplido. Esto es teología, mas en la rememoración nosotros tenemos una experiencia que nos prohíbe concebir la historia de manera fundamentalmente ateológica, si bien no se nos permita escribirla en conceptos inmediatamente teológicos» (GS, II, 1333).

Estamos convencidos de que en estas palabras se condensan algunos de los elementos más importantes de la concepción benjaminiana de la historia, cuyo foco está justamente en la posibilidad de una correspondencia, de una conjunción peculiar, que enlace pasado y presente en una constelación inseparable, gracias a la cual el pasado se redescubra actual y, por ende, incumplido. De hecho, es muy probable que mientras escribía estas palabras, Benjamin tuviese presente una de las tesis que su amigo Scholem había pensado en regalarle en 1918, para su cumpleaños número 26: «El tiempo del w hahipuk [inversión] es el tiempo mesiánico» ${ }^{2}$. Como recuerda Agamben, el sistema verbal hebraico distingue las formas verbales no tanto según los tiempos — pasado, presente-, sino según los aspectos — cumplido, incumplido-; y el $w$ de inversión transforma la calidad de la acción indicada por la forma verbal, de suerte que se podría decir que agregando el $w$ hahipuk la acción cumplida se vuelve incumplida, mientras que la incumplida se presenta como cumplida. Si esto es así, el tiempo del Eingedenken es el tiempo mesiánico por excelencia, pues es el tiempo de la inversión de los modos del tiempo, en el cual pasado y presente, «así fue» y «no aún», se entrelazan generando un cortocircuito, en cuyo relampagueo se cela la posibilidad de una redención del dolor y del sufrimiento de las generaciones de vencidos que nos han precedido. El tiempo del Eingedenken no es instante extra-temporal, no es un fuera-del-tiempo, sino más bien una contracción cargada de tiempo hasta estallar.

${ }^{1}$ En Benjamin, Walter (1977), Gesammelte Schriften, Frankfurt am Main, Suhrkamp Verlag, Bd. II, pp. 1332-33. La edición crítica de la obra benjaminiana comenzó en 1972, a partir de la colaboración de Th. W. Adorno y G. Scholem y se concluyó en 1989, gracias a H. Schweppenhäuser y Rolf Tiedemann. La edición, en siete volúmenes, no sigue un criterio cronológico, sino sistemático-formal. De ahora en adelante la citamos en el texto como GS, seguido por número de volumen y número de página (las traducciones al castellano de los textos son nuestras).

2 Scholem, Gerschom (1995), 95 Thesen über Judentum und Zionismus, en Zwischen den Disziplinen, Frankfurt am Main, Suhrkamp Verlag, pp. 287-95. 
Aquí está el punto de mayor divergencia entre la concepción benjamianiana de la temporalidad y la concepción de un autor que Benjamin amaba mucho, como Marcel Proust. Como recuerda Peter Szondi, a pesar de los muchos elementos en común que pueden encontrarse entre el escritor francés y el filósofo alemán, y a pesar de las innumerables imágenes proustianas diseminadas a lo largo de toda la obra de Benjamin, la búsqueda del tiempo perdido no persigue el mismo objetivo en estos pensadores. La afinidad es sólo aparente: «Proust se lanza en la búsqueda del tiempo perdido, que es el pasado, para intentar escapar [...] de los límites que el tiempo le impone. La búsqueda del tiempo perdido como pasado para Proust tiene como objetivo de la pérdida o disolución del tiempo como tal» ${ }^{3}$. La felicidad para Proust es algo extratemporal; posible sólo cuando una interferencia entre un momento del pasado y un momento del presente permite escapar a las amenazas del tiempo - a su caducidad - observar y gozar de las cosas en su esencia a-histórica; de ahí que el objetivo que el escritor francés persigue sea el de la liberación del terror de estar sometidos a las «leyes del tiempo». Benjamin, en cambio, no quiere deshacerse de la temporalidad, más bien busca en el pasado «las huellas del futuro». No se trata de una evocación de lo perdido para liberarlo, en el recuerdo, del peso insoportable del «así fue», sino antes bien de descifrar el futuro que ha quedado atrapado en el pasado, ese futuro que pudo ser y no fue, futuro sólo en potencia, que un shock o la ruptura de la tradición podrían hacer emerger. El pasado, entonces, no esta definitivamente concluido; debajo de las cenizas de lo que fue se esconden las brazas de lo nuevo, del noch-nicht. Y es por ello que «existe una cita secreta entre las generaciones pasadas y la nuestra»; es por ello también que «a nosotros, como a cada una de las generaciones que nos precedieron, se nos ha dado una débil fuerza mesiánica, sobre la cual el pasado tiene derecho» (GS, I.2, 692. Esta exigencia, escribe Benjamin, no es fácil de cumplir, mas sólo en tal búsqueda reside para el hombre una felicidad posible.

La peculiaridad de la reflexión benjaminiana, entonces, está en su intento de pensar el lugar temporal de ese pequeño milagro que es la felicidad, cuya imagen, se lee en las tesis Über den Begriff der Geschichte, «está impregnada del color del tiempo al cual hemos sido asignados». En un texto de los años 30, el filósofo alemán escribía: «Él [el ángel] aspira a la felicidad: el contraste en el cual el éxtasis de la unicidad, de la novedad, del aún no vivido, se une a la beatitud de la repetición, de la recuperación de lo vivido. Por ello para él la esperanza de la novedad no tiene otro camino que el del retorno, allí adonde conduce consigo a otro nuevo ser humano. Así como yo, apenas te he visto por primera vez, contigo he vuelto hacia allí de donde he venido» (GS, VI, 523). En las páginas siguientes analizaremos la estructura del tiempo mesiá-

3 Szondi, Peter (1978), Hoffnung im Vergangenen. W.B. und die Suche nach der vorlorenen Zeit, en Id., Schriften II, Frankfurt am Main, Suhrkamp Verlag, pp. 278 y s. 
nico que Benjamin intenta pensar, desde el punto de vista de su indisoluble conexión con los conceptos de felicidad y redención. El modo en el cual estos conceptos se conjugan con la figura tardía del Eingedenken determinan la especificidad y la riqueza de una reflexión sobre el tiempo y la historia en un contexto, como es el de la primera mitad del siglo XX, en el cual se multiplican los intentos de pensar una nueva forma de temporalidad, capaz de hacer estallar el tiempo lineal y cronológico que las ciencias del espíritu han tomado del modelo de las ciencias naturales. Nuestro recorrido se detendrá sobre todo en los escritos de juventud del filósofo alemán, pues ya en ellos la constelación felicidad-redención adquiere una fisionomía definida, conjugándose además con una crítica elegante y puntual de la modernidad como tiempo del dominio de lo mítico. Por otro lado, el análisis de los escritos y fragmentos juveniles debería permitirnos ver, en contraluz, el desplazamiento conceptual que la figura del Eingedenken introduce en la reflexión del filósofo.

\section{Divino y profano: la contracción del tiempo}

En 1932 Adorno realiza una conferencia en la Universidad de Frankfurt, cuyo título es Die Idee der Naturgeschichte. Aquí el filósofo de la Dialéctica negativa sostiene que la historia implica el «generarse de un elemento cualitativamente nuevo», es decir que el movimiento histórico no puede ser un movimiento que se resuelve «en pura identidad, en la mera reproducción de lo que ya existía, sino que hace surgir lo nuevo y alcanza su auténtico carácter justamente gracias a esta aparición de lo nuevo» ${ }^{4}$. El elemento crucial de la conferencia reside claramente en el intento de mostrar que la historia, hasta tanto siga presentándose como proceso privado de conciencia, quedará congelada dentro del horizonte de la historia natural, cuya concepción de la temporalidad se realiza bajo el signo mítico de la predeterminación y está sujeta a una dinámica ciega y fatal que no se deja reconducir a la auténtica racionalidad.

Fuente de inspiración de la conferencia es el texto benjaminiano sobre el drama barroco, que Adorno no deja de recordar. De hecho, el elemento de lo mítico constituye el punto nodal alrededor del cual se articula todo el diálogo intelectual entre ambos pensadores; elemento sobre el que Benjamin nos ha dejado algunas páginas sugestivas y profundas en la memorable obra sobre los Pasajes parisinos: «la esencia de lo mítico es la repetición, en la cual se inscribe como figura latente esa inutilidad que marca la frente de algunos héroes de los mundos inferiores (Tántalo, Sísifo y las Danaides). Pensando nuevamente, en el siglo XIX, la figura del eterno retorno, Nietzsche se presenta como aquél en quien la fatalidad mítica se cumple nuevamente. (La eternidad de la pena infernal matiza quizás el extremo más tremendo de la idea arcaica

${ }^{4}$ En Gesammelte Schriften (1970), Frankfurt am Main, Suhrkamp Verlag, Bd. I, p. 346. 
del eterno retorno, substituyendo con la eternidad del tormento la eternidad de un proceso cíclico)» $(G S$, V.1, 178). Lo mítico es entonces la petrificación de la vida en el círculo encantado del eterno retorno; no sólo en el sentido de que sucede siempre lo mismo, sino sobre todo en el sentido de que «el rostro del mundo no muta nunca justamente en aquello que constituye lo nuevo, es más, que lo nuevo, bajo todo punto de vista, es lo siempre igual» $(G S, \mathrm{~V} .1$, 651).

He aquí la dialéctica de lo nuevo y de lo siempre igual que en la Passagenarbeit Benjamin presenta como una de las imágenes de la modernidad ${ }^{5}$, cuyo signo más eficaz se encuentra en el ritmo penetrante de la moda, en las aceleraciones del tráfico y en la velocidad de transmisión de las noticias. Mas esta reproposición de lo nuevo en el contexto de lo que siempre fue, esta reduplicación infinita de lo mismo, es justamente lo que define a la modernidad como «edad del Infierno». Lo mítico es entonces lo infernal, en el sentido de ineluctable e in-finita reproducción de lo mismo en el espacio de la historia. Desde este punto de vista, lo mítico, en Benjamin como también en Adorno, parece estar íntimamente entrelazado con el concepto de destino, que indica justamente el sometimiento ciego a un elemento fatal, desde del cual no es posible concebir ninguna vía de liberación. El destino, escribe Benjamin en Destino y carácter (1919), se presenta «cuando se considera una vida como condenada»; el destino representa un orden cuyos elementos constitutivos son la infelicidad y la culpa. La esfera de lo mítico es, pues, la continuidad del destino como dominio sobre lo viviente; dominio que el joven Benjamin identifica con la esfera del derecho y de la violencia.

Siempre en Destino y carácter se lee: «¿es la infelicidad, como sin duda la desventura, una categoría constitutiva del destino? Justamente la felicidad es la que desvincula al feliz del engranaje de los destinos y de la red misma de su destino. No por azar Hölderlin llama sin destino a los dioses bienaventurados. Felicidad y beatitud conducen entonces, como la inocencia, fuera de la esfera del destino. Pero un orden cuyos únicos conceptos constitutivos son infelicidad y culpa, y desde el cual no es concebible camino alguno de liberación (pues en la medida en que algo está destinado es infelicidad y culpa), no puede ser religioso [...]» $(G S$, II.1, 174). Es necesario entonces buscar otro campo en el cual cuenten sólo infelicidad y culpa, «una balanza sobre la cual beatitud e inocencia resultan demasiado livianas y se libran hacia arriba. Esa balanza es la balanza del derecho. Las leyes del destino, infelicidad y culpa, han sido puestas por el derecho [...]. Por un error, puesto que ha sido confundido con el reino de la justicia, el orden del derecho, que es sólo un residuo

5 «Definición de la Modernidad como lo nuevo en el contexto de lo que siempre fue. El paisaje de brezales siempre nuevo y siempre igual a sí mismo de Kafka (El proceso) es una expresión eficaz de esta situación [...]» $(G S$, V.1, 650). Sobre este tema, cf. el texto de Desideri, Fabrizio (2001), «Teologia dell'inferno. Walter Benjamin e il feticismo moderno»; en Mistura, Stefano, Figure del fetichismo, Torino, Einaudi, pp. 175-196. 
del estado demoníaco de la existencia de los hombres, en cuyos estatutos jurídicos no se reglamentaban solamente las relaciones entre ellos, sino también su relación con los dioses, se ha conservado más allá de la época que inauguró la victoria sobre los demonios» $(G S, \mathrm{II} .1,174)$. El orden de lo mítico es el orden de la repetición perpetua de la secuencia culpa-castigo, en un ciclo en el que cada momento, configurando una nueva culpa y una nueva maldición, reclama al infinito una nueva expiación ${ }^{6}$. El orden de lo mítico es el orden del dominio de la apariencia, que sobrevive aún en la esfera del derecho. No es por azar, escribe Benjamin en el fragmento 71, conocido como El significado del tiempo en el mundo moral, que las instituciones del derecho permiten establecer hecho y justicia respecto de épocas anteriores; pero «lo que le confiere al derecho este interés y este poder sobre el pretérito remoto - lejos de representar la presencia en él de la moral- es más bien una inclinación que lo separa nítidamente del mundo moral: la inclinación a la revancha. [...] La revancha, en el fondo, se erige con soberana indiferencia respecto del tiempo, en la medida en que queda en vigor sin disminución alguna a través de los siglos [...]» (GS, VI, 97) ${ }^{7}$.

Esta polémica contra la esfera del derecho como esfera de la condena eterna de lo viviente a la culpa y a la maldición reaparece en un texto de algunos años más tarde, cuyo título es Zur Kritik der Gewalt. Como en el fragmento apenas citado, también aquí el mundo del derecho es concebido como un mundo dominado por la «revancha», al cual le es inaccesible «el inconmensurable significado» del día del juicio. La esfera del derecho es inseparable de la violencia, pues sólo la violencia es creadora de derecho: «Instauración de derecho equivale a instauración de poder, y es, por ende, un acto de manifestación inmediata de la violencia» $(G S$, II.1, 197). La violencia que co-

6 Esta imagen del mundo mítico como mundo de la culpa y del castigo, como mundo dominado por el destino, está presente también en el fragmento 74 (escrito probablemente a mediados de 1921). Sin embargo, es interesante observar que aquí Benjamin lo identifica con el capitalismo: «En el capitalismo hay que ver una religión» y una de las características más importantes de esta estructura religiosa, además de la de ser una pura religión cultual, y de constituirse como religión en la que no existe día laboral, pues todos los días son días festivos, es que el capitalismo es religión generadora de culpa: «El capitalismo probablemente representa el primer caso de un culto que no elimina el pecado, sino que genera culpa. [...] Una inmensa conciencia de culpa, que no sabe liberarse del pecado, que recurre al culto no para expiar a través suyo la culpa, sino para volverla universal, para machacarla en la conciencia y sobre todo para incluir a Dios mismo en esta culpa, finalmente para incluirlo en la expiación» (GS, VI, 100).

${ }^{7}$ El inconmensurable significado del día del juicio «no se presenta en el mundo del derecho, dominado por la revancha, mas sólo allí adonde ésta encuentra el perdón, en el mundo moral»; y aun: «el significado del tiempo en la economía del mundo moral, en el cual el tiempo extingue no sólo las huellas del crimen, sino además, con su duración —-más allá de todo recordar u olvidar - contribuye de manera totalmente misteriosa al perdón, si bien jamás a la reconciliación» (GS, VI, 98). Probablemente el fragmento debe ser colocado cronológicamente entorno al 1921, pues hay en él varias asonancias con la parte final de Zur Kritik der Gewalt. 
mienza como expresión de fuerza concluye su ciclo sólo imponiéndose como poder, manifestando su dominio en la forma del derecho. No existe derecho, entonces, en cuyas raíces no haya fuerza (poder) y violencia. Mas la función de la violencia creadora de derecho no desaparece cuando ha alcanzado su objetivo, es decir, cuando ha logrado establecerse como poder, cristalizando en normas y leyes sus propios fines. De hecho, de ahora en adelante, escribe Benjamin, la fuerza que se ha instaurado como derecho y, por ende, como poder, debe ser garantizada y protegida por esta misma violencia creadora. Es más, sólo ahora se convierte, en el sentido más estricto, en violencia creadora de derecho, pues instaura como derecho, con el nombre de poder, no un fin inmune e independiente de la violencia, sino un fin íntima y necesariamente ligado a ella» (GS, II.1, 197).

A la esfera del derecho Benjamin contrapone la esfera de la justicia: «justicia es el principio de toda finalidad divina; poder, el principio de todo derecho mítico» $(G S$, II.1, 198). Y añade: «si la violencia mítica instaura el derecho, la divina lo aniquila; si aquélla establece límites y fronteras, ésta destruye sin limitaciones; si la violencia mítica culpa y castiga, la divina exculpa; si aquélla es amenazante, ésta es fulmínea; si aquélla es sangrienta, ésta es letal sin derramar sangre» $(G S$, II.1, 199). La violencia divina es violencia pura, violencia que tiene un impacto absolutamente destructivo, aniquilador y fulmíneo sobre la esfera terrenal ${ }^{8}$. La violencia divina no contrata, no instaura equivalencias; su principio no es el del intercambio, sino más bien el principio purificador del perdón, que atraviesa la historia, barriendo todas las huellas del crimen, de la angustia y de la culpa; como un huracán que devasta la tierra, aun cuando fuere para borrar todo residuo de culpa ${ }^{9}$. No existe, pues, ninguna posibilidad de «comercio» entre la violencia sangrienta y

8 La reflexión benjamianiana sobre la justicia y su contraposición con la esfera del derecho, como esfera de la apariencia mítica, está íntimamente ligada a la suprema importancia que la categoría de la justicia conserva en el hebraísmo. De hecho, la reflexión sobre la justicia como cualidad fundamental de la condición divina constituye uno de los temas centrales de las conversaciones entre Benjamin y Scholem durante el primer período de su amistad. En los Diarios del estudioso de mística hebraica encontramos varios fragmentos de estas discusiones, aunque es difícil establecer si tales reflexiones pertenecen sólo al filósofo alemán o son el resultado de una personal reelaboración scholemiana de aquellas largas tardes de discusión; sobre este tema, cf. Bonola, Giorgio (2000), «Antipolitica mesiánica. La giustizia di Dio come critica del diritto e del "politico" nel filosofare comune di G. Scholem e W. Benjamin (1916-1920)», en Fenomenologia e società: Walter Benjamin: pensare la storia, n. 2, año XXIII, pp. 3-36.

9 «De hecho, el tiempo en el cual Ate persigue al malhechor no es la bonanza solitaria de la angustia, sino la sonante borrasca del perdón que precede rugiendo al juicio (Gericht) siempre inminente, contra el cual nada puede. Esta borrasca no es sólo el sonido dentro del cual se desvanece el grito de angustia del malhechor; es también la mano que borra las huellas de su «crimen», aun cuando para ello tuviese que devastar (verwüsten) la tierra. Como el huracán purificador anticipa la borrasca, así la cólera de Dios ruge a través de la historia en la borrasca del perdón (Vergebung) para eliminar todo lo que debería ser fulminado para siempre por los rayos de la tempestad divina» (GS, VI, 98). 
dolorosa de la esfera de la apariencia mítica y la violencia pura e inmediata de lo divino. Mientras que la primera apunta a crear y a sostener el perdurar del derecho y del poder, la segunda tiene un impacto destructivo y arrasador. La esfera divina se realiza en la esfera de lo profano sólo en la forma de una «borrasca», de un huracán, que se traga definitivamente las huellas del crimen y del dolor ${ }^{10}$. No hay, entonces, una realizabilidad «positiva» de la justicia divina; no es lícito hablar de una realización o cumplimiento, en la dimensión profana, de lo divino como tal. Todo el esfuerzo de Benjamin apunta a salvaguardar la alteridad radical existente entre estas dos dimensiones. En el fragmento 73 se lee: «[...] allí donde el poder divino penetra en el mundo terreno, éste respira destrucción (Zerstörung). Por ello, en este mundo, no ha de fundarse nada de duradero y ningún orden sobre la base de aquél; ni hablar del dominio (Herrschaft) como su principio supremo» (GS, VI, 99) ${ }^{11}$.

La imposibilidad de fundar algo duradero sobre la base del poder divino decreta, para Benjamin, la falsedad de toda forma de teocracia. También en el Theologisch-politisches Fragment el filósofo insiste sobre la imposibilidad de fundar el poder teológicamente y sobre la insensatez del concepto mismo de teocracia; lo divino no puede ofrecer ningún fundamento a las formas de dominación, pues «Sólo el Mesías mismo consuma (vollendet) todo suceder histórico, y en el sentido precisamente de crear, redimir, consumar su relación para con lo mesiánico» $(G S, \mathrm{II} .1,203)$. Por ello, lo que pertenece a la esfera de la historia no puede querer ponerse por si mismo en relación con lo mesiánico; el contacto entre divino y profano no es un resultado de lo profano y por ello nada en la esfera de lo profano puede erigirse apuntando a la idea del Reino de Dios como su meta o como su tarea última: «El Reino de Dios no es el telos de la dynamis histórica; no puede ser colocado como meta. Desde el punto de vista histórico no es la meta, sino el fin» (GS, II.1, 203). Otra vez, entonces, el abismo entre profano y divino. La llegada del Mesías consuma el suceder histórico, mas en el sentido de que implica el fin de este último; el Mesías conduce la historia a su cumplimiento y, por ende, a su resolución.

${ }^{10}$ La imagen de la tormenta, de la borrasca, retorna muchas veces a lo largo de la obra benjaminiana; de ahí que no sea casual que la volvamos a encontrar en la célebre tesis novena de Über den Begriff der Geschichte, que constituye el corazón mismo de las tesis. Scholem insiste mucho sobre el carácter catastrófico del evento mesiánico en su texto sobre la idea mesiánica en el hebraísmo: «El mesianismo judío es en sus orígenes y por su naturaleza [...] una teoría de la catástrofe. Esta teoría subraya el elemento revolucionario y cataclísmico en la transición de todo acontecimiento histórico presente hacia el futuro mesiánico», Scholem, Gershom (1971), The Messianic Idea of Judaism and Other Essays on Jewish Spirituality, New York, Schocken Books, p. 7. Otro de los elementos fundamentales del concepto hebraico de redención sería el carácter público de esta última: para el hebraísmo, escribe Scholem, se trata de un evento que tiene lugar en el escenario de la historia, en el mundo visible y dentro de la comunidad.

11 «(En este mundo la violencia divina es superior a la no-violencia divina. En el mundo por venir la no violencia divina es superior a la violencia divina). Tal manifestación ha de buscarse no en la esfera de lo social, sino en la de la percepción reveladora y, al final, y sobre todo, en la de la lengua y con prioridad, en la de la lengua sagrada» (GS, VI, 99). 
Como en el fragmento Mundo y tiempo, en el devenir manifiesto de lo divino en el mundo, éste queda sometido a un gran proceso de descomposición. La redención de la historia significa, entonces, que ella ha agotado su función y alcanza su cumplimiento y su desaparición.

La diferencia radical ente profano y divino hace imposible para lo profano un acercamiento positivo y progresivo al Reino. Éste, como la justicia, no puede constituir un objeto de posesión para la criatura; mucho menos puede presentarse como ideal o deber infinito. El Reino no es un concepto límite que indica un deber realizable sólo al infinito, sino un ad-veniente que detiene la dinámica histórica. Entre el ámbito intrascendible de la esfera de lo creado y el orden mesiánico no hay entonces relación directa o lineal; el orden de lo profano no procede hacia el Reino y no es posible construir un itinerario de acercamiento progresivo al Reino mesiánico. Por ende, no hay en Benjamin, ni habrá durante todo el arco de sus reflexiones sobre la historia, ninguna inclinación hacia un mesiánico entendido en el sentido neokantiano de unendliche Aufgabe ${ }^{12}$. Tampoco hay $-\mathrm{y}$ Benjamin se mantendrá fiel a esta concepción hasta sus últimas Tesis - ninguna forma de te-

12 Cf. tesis XVIIa, en GS, I.3, 1231. Marramao sostiene que el mesianismo benjaminiano no puede considerarse cercano al concepto kantiano o neokantiano de Ideal, pues la concepción de Benjamin se coloca por fuera del «Futurismus occidental, cuyos símbolos son, por un lado, la promesa de la salvación de las religiones monoteístas y, por el otro, la Fortschrittsgläubigkeit de la moderna filosofía de la historia». Desde este punto de vista, el mesianismo benjaminiano se constituye como un «mesianismo sin espera» y aquí residiría uno de los elementos más innovadores y radicales de la teología política del pensador alemán; Marramao, Giacomo (2005), «Messianismo senza attesa. Sulla teologia politica di Walter Benjamin», en Aut-Aut, n. 328, pp. 119-134. Massimiliano Tomba, en cambio, sostiene que es posible pensar la reflexión kantiana como cercana a la reflexión de Benjamin, sobre todo respecto de la cuestión de la justicia y de la relación justicia-derecho. En Kant el desfase incolmable entre Idea y realidad - en lenguaje benjaminiano: entre divino y profano - implica la imposibilidad de lo fenoménico de presentarse como adecuado a la Idea, y abre de este modo, al menos quoad nos, el espacio infinito de una práctica llamada a medirse siempre con la instancia ideal. La concepción kantiana desplaza el baricentro desde la realización de la idea a la praxis conforme a la idea; es decir que la Idea no puede entenderse como mero ideal, meta o fin que debe realizarse al infinito y que, como tal, se presenta como justificación de los medios necesarios para su cumplimiento. Justamente lo que aquí salta es la relación medios-fines, pues criterio de la justicia de la acción es sólo la participación de ésta última en la instancia universal; participación que no puede ser juzgada diacrónicamente, sino sólo sincrónicamente. La afinidad Benjamin-Kant estaría entonces no sólo en el hecho de que ambos pensadores permiten la reapertura de la pregunta sobre la justicia y su relación con el derecho, sino además en el hecho de que el cuadro teórico que los dos filósofos trazan impone una reconsideración radical del binomio teoría-praxis, que se substrae a la Zweck-Mittel Relation, típica de gran parte de la racionalidad moderna; Tomba, Massimiliano (2006), La «vera politica». Kant e Benjamin: la possibilità della giustizia, Macerata, Quodlibet; cf. también Folkers, Horst (1979), «Zum Begriff der Gewalt bei Kant und Benjamin», en Figal, Gunter y Folkers, Horst (ed.), Zur Theorie der Gewalt und Gewaltlosigkeit bei Walter Benjamin, Heidelberg, Fest, pp. 25-57.

13 Jacob Taubes en su seminario sobre las Tesis de filosofia de la historia afirma que «Benjamin introduce la idea del fin en el tiempo mismo. Y esto significa una irrupción puntual e improvisa [...] Benjamin no sostiene ningún tipo de futurologismo mesiánico; antes bien, el 
leología escatológica ${ }^{13}$. Sin embargo, la diferencia infinita entre la criatura y Dios, entre histórico y eterno - diferencia que, como hemos dicho, hace imposible la construcción de un camino orientado hacia el Reino- tampoco genera una forma de «indiferencia escatológica». En sus Diarios, Scholem anota algunas reflexiones benjaminianas sobre la justicia, tratando de integrarlas con la tradición hebraica: «La esencia de la idea hebraica de la justicia como «esfuerzo de hacer del mundo el bien supremo» como escribía Benjamin, se exprime profundamente en las palabras casi intraducibles de los sabios que Hirsch asocia a Gen. 24,1: Zadichim jachinu schichinah ba arez (los justos prepararán la [llegada de la] schechinah sobre la tierra), traduciéndolo muy bien - de este modo es posible recuperar una parte del significado, un matiz que suena como si Benjamin lo hubiera conocido: los justos prepararán la tierra para que en ella pueda morar lo divino. Esto es justicia; hacer que la tierra se convierta en la sede de la schechinah, atraer la schechinah hacia abajo» ${ }^{14}$.

Se trata, entonces, en la interpretación scholemiana de Benjamin, de preparar la tierra para la llegada del Mesías. Los justos son aquéllos que ponen todo su esfuerzo en hacer de la tierra un lugar digno. Con su acción, ellos «llaman» (rufen) al Mesías, invocan su justicia. Queda claro entonces que la imposibilidad del orden profano de acercarse al orden de lo divino, su incapacidad de producir por sí solo la relación con la potencia eterna de la justicia divina, no implica un complacerse o abandonarse a la intrascendible «mundaneidad» de lo creado; no implica, justamente, ninguna indiferencia, sino más bien un esfuerzo para hacer que el orden mundano se vuelva digno de lo divino, para prepararlo para la presencia de la schechinah. Y es por ello que también en el Theologisch-politisches Fragment, a pesar de la distancia que establece entre profano y divino, Bejamin no niega la posibilidad de una relación entre estos dos órdenes. Si el abismo no pudiese ser colmado, no existiría siquiera la posibilidad de la salvación. No se daría redención.

El orden de lo profano, escribe Benjamin siempre en el Fragmento, puede ser construido teniendo como meta, no la idea del Reino de Dios, sino la de la felicidad: «Si la dirección de una flecha indica la meta hacia la cual se dirige la dynamis de lo profano, y otra, la dirección de la intensidad mesiánica, resulta entonces que la búsqueda de la felicidad de la humanidad libre se aleja ciertamente de tal dirección mesiánica; ahora bien, al igual que una fuerza puede favorecer, en su trayectoria, a otra fuerza que va en sentido opuesto, así también el orden profano de lo profano puede favorecer la venida del reino

suyo es un actualismo mesiánico», «Walter Benjamin: Geschichtsphilosophische Thesen (Seminar - Wintersemester 1984'85)», en Taubes, Jacob (2006), Der Preis des Messianismus, (ed. a cargo de E. Stimilli), Würzburg, Königshausen \& Neumann, pp. 67-92.

14 Scholem, Gershom (1995), Tagebücher nebst Aufsätze und Entwürfe bis 1923, I. Halbband 1913-1917 (hrsg. von K. Gründer und F. Niewöhner), Frankfurt am Main, Jüdischer Verlag, p. 419. 
mesiánico. Lo profano no es en efecto una categoría del Reino, pero sí una categoría - y por cierto una de las más pertinentes — de su más quedo acercamiento» (GS, II.1, 204). Sólo la felicidad puede constituirse como el telos de la dynamis histórica. Pero la búsqueda de la felicidad, si bien no puede promover directamente la venida del Reino, puede hacerlo de manera indirecta. La felicidad se presenta de este modo como la aliada más fiel del Reino. Añade Benjamin: «De hecho en la felicidad todo lo terreno aspira al ocaso, y sólo en la felicidad está destinado a encontrarlo [...] A la restitutio in integrum espiritual, que conduce a la inmortalidad, le corresponde una restitutio in integrum mundana, que a su vez conduce a la eternidad de un ocaso (Untergang[es]); y el ritmo de esta mundaneidad que pasa eternamente (ewig vergehenden), que pasa en su totalidad, en su totalidad espacial y temporal, el ritmo de la naturaleza mesiánica es la felicidad. Pues la naturaleza es sin duda mesiánica por su pasar eterno y total (aus ihrer ewigen und totalen Vergängnis» (GS, II.1, 204).

Imágenes muy intensas ilustran lo que el mismo Benjamin llama «concepción mística de la historia». Concepción a la cual el pensador alemán se mostrará siempre fiel; aunque, como veremos, las últimas tesis introducen en este cuadro teórico algunos imperceptibles desplazamientos conceptuales. Por ahora volvamos al Fragmento. ¿Por qué Benjamin escribe que la felicidad constituye el fulcro en virtud del cual el orden profano puede transformarse en la categoría más idónea de acercamiento al Reino? ¿en qué sentido y de qué forma la felicidad conspira, aunque de manera indirecta, hacia el Reino? y sobre todo, ¿qué significa que la felicidad es el ritmo de un ocaso, de un pasar eterno y total? Es necesario entonces indagar la correspondencia de «restitutio in integrum espiritual» y «restitutio in integrum mundana». Esta última, dice Benjamin, se caracteriza por su «Vergehen» continuo e inagotable; mas en la visión benjaminiana, tal transire eterno no define la condena de lo viviente. La caducidad no aparece en ningún momento ligada al pecado que lleva consigo la maldición de la degradación y de la muerte. Al parecer, es todo lo contrario: la caducidad refrenda el carácter mesiánico del ámbito de lo creado. De hecho, escribe el joven Benjamin, la naturaleza es mesiánica justamente por su pasar eterno y total. Y la transitoriedad de todas las cosas que pasan y se declinan eternamente traza un movimiento, cuyo ritmo es la felicidad. Esta es el motor que empuja el movimiento de la historia profana, es su intentio más íntima; pero no, como veremos mejor, en el sentido de que la felicidad constituya una suerte de sucedáneo de la redención, concedida a la criatura, como si se quisiera afirmar la posibilidad para lo viviente de aferrar, en la felicidad, un modelo débil de la salvación, o un pálido reflejo de la misma.

Es probable que la convicción de la alteridad radical entre profano y divino haya permitido a Benjamin pensar la felicidad en un sentido aún más extremo, que quizás podamos aferrar volviendo nuestra mirada a las palabras 
que el filósofo dedica a la obra de Kafka. En el memorable texto del 34, Benjamin cita el siguiente pasaje kafkiano: «la vida es extraordinariamente corta. En mi recuerdo es de tal brevedad que yo, por ejemplo, no comprendo cómo un joven pueda decidirse a ir a caballo hasta el poblado vecino sin temer que - más allá de cualquier desgraciado accidente - el lapso de una vida común, que fluye felizmente, sea infinitamente demasiado breve para tal cabalgata». $\mathrm{Y}$ añade que «a la vida que es demasiado breve para una cabalgata, corresponde esta cabalgata que es suficientemente larga para una vida: ... "hasta que no se arrojan las espuelas, pues no hay espuelas, hasta que no se arrojan las riendas, pues no hay riendas, y no se ve más que el campo frente a sí, como una landa pelada, ya sin el pescuezo y sin la cabeza del caballo"» $(G S$, II.2, 433). Demasiado larga es la cabalgata sólo para el caballero que, atado a su rocín, se propone una meta, un objetivo futuro, aun cuando fuere «el más próximo e inmediato»; demasiado larga para aquél que, no habiendo comprendido que hay esperanza, «infinita esperanza, pero no para nosotros», se obstina en atarse a sus posesiones, a los triunfos y a las futuras conquistas y no se da cuenta de que sólo quien deja ir las riendas, que no existen, el viaje se vuelve «alegre y vacío, y no es más una carga para su corcel» $(G S$, II.2, 436). Sólo para quien se echa a andar en una cabalgata que marcha contra ella misma, sopla el viento mesiánico. Sólo para quien, sin esperar, con paciencia atiende. Como los locos, o los ayudantes de Kafka, que no duermen nunca: como los estudiantes que velan siempre, porque la virtud suprema del estudio reside justamente en tener despiertos. Curvos, sin aliento sobre estudios que «no significaron nada», ellos vigilan, pues alguien debe hacerlo; alguien tiene que estar presente.

La felicidad, entonces, no se puede pensar bajo el signo de la posesión o de la conquista; mucho menos como posibilidad de aferrar una cifra anticipadora, aunque débil, de la salvación. En Benjamin, dice Taubes, no hay espacio para la analogía, para el kantiano «como si»; y aquí, según el estudioso de hebraísmo, se consuma la distancia sideral que existe entre la concepción benjaminiana del Mesías - contrapuesta a toda neutralización o domesticación de su venida - y la versión del mesianismo que nos ofrece Adorno en el último aforisma de Mínima moralia: la figura dominante del texto adorniano es el «als $o b$ » kantiano y por ello el de Adorno sería un «mesianismo estetizante», que nada tiene que ver con el «mesianismo substancial» de Benjamin, cuya cifra podemos rastrear sólo en el «hōs $m \bar{e} »$ paulino ${ }^{15}$. El de Adorno sí puede considerarse como un «mesianismo sin Mesías»; el de Benjamin no,

15 Cf. Taubes, Jacob (1993), Die politische Theologie des Paulus, München, Fink Verlag, pp. 103-04; véase también «Walter Benjamin: Geschichtsphilosophische Thesen», op. cit., p. 70. Sobre esta intuición taubesiana, Agamben basa su lectura del hōs mē paulino como fórmula de la vida mesiánica, traduciéndolo con una expresión que la estructura del castellano vuelve casi imposible («come non»), pues el español no siempre permite el participio presente de los verbos de la frase. 
pues «una cosa queda ante todo clara: existe un Mesías [...] Nada de nebulosas neutralizaciones iluministas o románticas» ${ }^{16}$.

A ello se debe que la felicidad de la que habla Benjamin en el Fragmento, aunque se ponga como meta de la dynamis profana, no puede ser construcción erecta y estable, sino que hay que entenderla en el sentido de la caducidad, bajo el signo del ocaso o del transire que, como decíamos antes, se parece a una cabalgata sin puntos de apoyo; bajo el signo de un desplazamiento inagotable, de una revocación incesante, de la anulación de toda posesión y de todo contenido. Ocaso es aquí la cifra del tiempo mesiánico en el sentido de la destrucción, o, mejor aún, del despojo de todo rol, de toda función o meta, de toda objetividad. Pasar, decaer es la desposesión que se abandona a la propia insuperable mundaneidad, a una suerte de "grado cero» en el cual las mediaciones o compromisos dialécticos devienen inoperantes y sólo queda el gesto en su pureza vacía. No es casual que en las últimas palabras del Fragmento Benjamin afirme que la política mundial, «cuyo método debe llamarse nihilismo», tiene que esforzarse para propender hacia ese «pasar». Caducidad y ocaso que recuerdan el nietzscheano «aspirar al propio ocaso», pero que tienen su antecedente más directo en la advertencia de Pablo, I Cor. 7, 29-32: «Esto os digo hermanos, el tiempo se ha contraído; por lo tanto los que tienen mujer vivan como los que no tienen y los que lloran como los que no lloran, y los que tienen alegría como los que no la tienen y los que compran como los que no poseen y los que usan el mundo como los que no abusan. Pasa la figura de este mundo. Os quiero sin cuidado».

\section{Jetztzeit: el gesto rememorante}

Casi veinte años separan al Theologisch-politisches Fragment de las tesis Über den Begriff der Geschichte. Veinte años durante los cuales el horizonte teórico benjaminiano ha ido matizándose y enriqueciéndose con nuevas experiencias: el acercamiento al teatro de Brecht y a la escritura surrealista; el encuentro con el materialismo histórico y con la experiencia cinematográfica soviética; la guerra y el exilio, que generan en el pensador una sensación de claustrofobia y de soledad extrema. Poco antes de su trágica muerte en la frontera española escribe: «El aislamiento en el que vivo desde siempre ha sido agigantado por las circunstancias del tiempo. El residuo de intelecto que, después de todo lo que han soportado, aún les queda a los judíos, no parece demasiado sólido. El número de personas que está a gusto en este mundo se va reduciendo cada vez más [...]» ${ }^{17}$.

16 Taubes, Jacob, Die politische Theologie des Paulus, op. cit., p. 98.

17 Carta del 11 de enero de 1940, en Benjamin, Walter y Scholem, Gershom, Briefwechsel 1933-1940, (ed. a cargo de G. Scholem), Suhrkamp, Frankfurt am Main 1980. 
En este contexto moral Benjamin redacta las tesis Über den Begriff der Geschichte. Escrito concebido en un estado de precariedad y caracterizado por la situación mundial de emergencia, las Tesis constituyen un documento de interrogación radical sobre la historia y sobre el concepto de tiempo sobre el cual ésta se funda. Como en el Fragmento y en los otros escritos de juventud, el filósofo niega con firmeza una imagen de la historia como proceso, como marcha hacia adelante, o como perfectibilidad infinita de la humanidad $\mathrm{y}$ de sus conquistas. Escribe en la tesis número 13: «La teoría socialdemócrata, y más aún su práctica, ha sido determinada sobre un concepto de progreso no atinente a la realidad y con pretensiones dogmáticas. El progreso, imaginado en las mentes socialdemócratas era, en primer lugar, el progreso de humanidad en sí misma (y no sólo un avance en las capacidades y conocimientos del hombre). En segundo lugar, era un progreso sin término (correspondiente a la infinita perfectibilidad de la humanidad). En tercer lugar, valía como irresistible (algo que automáticamente describía un curso directo o espiral). Cada uno de estos enunciados era, en realidad, controvertido y susceptible de crítica. Sin embargo, si ha de ser inclemente, la crítica debe penetrar más allá de estas afirmaciones y centrarse en lo que tienen en común. La idea de progreso del género humano en la historia es inseparable de la idea según la cual la historia procede atravesando un tiempo homogéneo y vacío. La crítica a la idea de tal proceder debe ser la base de toda crítica a la idea de progreso en sí mismo» (GS, I.2, 700-01).

Benjamin renueva entonces aquí su rechazo a la representación de la historia como totalidad objetiva que se mueve teleológicamente hacia la perfección. La categoría de progreso, como marca del curso de la historia en su totalidad, congela el tiempo histórico dentro de leyes inmutables que explican todo acontecimiento histórico a la luz de una supuesta mejoría futura, la cual, a su vez, resulta útil a la justificación de todo lo «inoportuno y doloroso» que la historia encierra, el horror inmenso y las mutilaciones deformantes que en ella tienen lugar. No es todo. Dentro de una concepción de este tipo, el espacio del presente termina enredado en una suerte de torbellino infernal «que lo arrastra irresistiblemente hacia el futuro», transformándolo en un mero puente entre lo que ha sido - y que por ende no es más que muerta posesión- $-\mathrm{y}$ lo que será - que se configura, a su vez, como un «así fue», pues resulta predeterminado de antemano-. Es por esto que la historia bajo el signo del progreso no es más que historia congelada dentro del dominio de la apariencia mítica, dentro del dominio del destino, en el cual no hay espacio para la redención. Mas sin redención no hay historia, sino sólo una perpetua ciclicidad, el eterno retorno de lo idéntico, que es la anulación del tiempo, pues es mera estaticidad: puro espacio cartesiano sin tempo, siempre igualmente lleno e igualmente vacío. En la última tesis se lee: «[...] Se sabe que a los Judíos les estaba prohibido investigar el futuro. La Torah y las plegarias en cambio los instruyen en la rememoración [Eingedenken]. Esto los liberaba del encanta- 
miento del futuro, bajo el cual sucumben todos aquellos que buscan respuestas en los adivinos. Sin embargo, el futuro no se convirtió para los judíos en un tiempo vacío y homogéneo. Porque en él cada segundo era la pequeña puerta por la cual podía entrar el Mesías» (GS, I.2, 704).

Aquí, como ya en el Theologisch-politisches Fragment y en los fragmentos de los años 20, la venida del Mesías irrumpe en la historia. No puede ser calculada ni prevista; puede ser solamente invocada. Es por ello que Benjamin previene contra esa hipertrófica futurización del tiempo, típica de la Modernidad que, como habría de decir Koselleck algunos años más tarde, termina por tragar «el espacio de la experiencia» dentro del «horizonte de las expectativas», aniquilando de este modo el presente como «lugar» $\mathrm{y}$ «tiempo» de la acción. Esto quiere decir que si el proyecto «progresivo» que inaugura el mundo moderno implica el sacrificio del presente y de la experiencia en nombre del por-venir - por-venir concebido bajo el signo de la perfectibilidad infinita e irresistible de la humanidad-, en el tiempo de la entropía híper-moderna, la aceleración cada vez mayor de un tiempo completamente irreversible impone, en cambio, un sofocamiento de esa apertura que el futuro, como «horizonte temporal de un fin determinado», representaba. El tiempo de la entropía, escribe Koselleck, no es más que el tiempo del «futuro pasado», tiempo en el cual el futuro se presenta a los individuos como consumido de antemano; existe sólo para transformarse en pasado, para ser suprimido, para desaparecer en la asfixiante estancia del «así fue» y terminar alimentando el suculento botín que forma el museo de la historia ${ }^{18}$.

Ante esta situación, escribe Benjamin, el materialista histórico debe esforzarse para pensar una nueva temporalidad, pues la noción de continuum temporal sobre la cual se erige la concepción historicista no sólo es incoherente y imprecisa, sino que además, en cuanto la ilusión de la progresividad y de la calculabilidad de la perfección humana se disuelve, muestra su rostro más dispersivo y caótico. He aquí que el continuum temporal se muestra en toda su vacua ferocidad, como inexorable fluir que no está ni lleno, ni vacío, pues, como dice Bloch en sus Differenzierungen im Begriff Fortschritt, «es por dondequiera igualmente denso o, como cosa abstracta, igualmente vacuo». Es por eso que se deja transformar en serie numérica, en el tiempo cronológico del reloj, absolutamente indiferente a sus propios contenidos; puro no-ser, en el cual la puerta a través de la cual puede entrar el Mesías queda definitivamente sellada. Pero ¿en qué difieren este tiempo, que no conoce otra cosa más que la furia de un desvanecerse incesante, y el tiempo como eterno pasar, del que hablaba Benjamin en el Fragmento teológico-político? ¿O es que la transitoriedad ya no define el carácter mesiánico de la criatura

18 Cf. Koselleck, Reinhart (1979), Vergangene Zukunft. Zur Semantik Geschichtlicher Zeiten, Frankfurt am Main, Suhrkamp Verlag. Sobre el mismo argumento, cf. también Marramao, Giacomo (1995), Potere e secolarizzazione. Le categorie del tempo, Roma, Editori Riuniti. 
para el Benjamin de las Tesis? Como afirma Jacob Taubes, el tema de la caducidad constituye un ductus siempre presente en Benjamin; también aquí, en las Tesis. La diferencia, o si se quiere, la novedad, es que ahora el carácter mesiánico de lo profano se cumple en el enlace entre el desvanecerse del presente y el «hilo de paja» del Eingedenken, el único que puede «salvar» a los eventos para que no se los trague la pesada piedra del «así fue», del perfectum, de lo ya concluido. Esta sutil urdimbre conceptual, en la cual la débil fuerza mesiánica de la «rememoración» se ciñe alrededor de una concepción del tiempo como discontinuum, marca la diferencia entre las Tesis y los escritos benjaminianos juveniles sobre la historia. Además, en esta débil fuerza mesiánica que el Eingedenken nos concede está el secreto de la posibilidad de pensar la felicidad como unida indisolublemente con la idea de la redención.

Afirmar la transitoriedad, el devenir, el pasar de la figura del mundo, no significa sostener una imagen del tiempo como continuum homogéneo y vacío, pura forma que fluye indiferente al propio contenido. Al contrario. A ese fluir infinito y abstracto, el filósofo berlinés opone la ruptura de la unidad temporal, el instante, como «lugar» que retiene en sí todo el devenir. Para Benjamin, escribe Fabrizio Desideri, el continuum «es la antítesis más poderosa del devenir»; es la forma del tiempo mítico, el tiempo de la repetición inagotada e inagotable, que no concede el jamás, que no conoce grietas; pero que, justamente por esto, no conoce la posibilidad de lo nuevo. Pues es este jamás, que acuna y envuelve al tiempo bajo la amenaza de una irremediable caducidad, el que hace que el instante adquiera un rostro destellante, única posibilidad desvaneciente de redención. Y esta posibilidad le pertenece a aquella débil fuerza mesiánica que nos ha sido otorgada y sobre la cual «el pasado tiene derecho», la rememoración: «El pasado lleva un índice oculto que no deja de remitirlo a la redención. ¿Acaso no nos acaricia también a nosotros un soplo del aire que rozaba a quienes estuvieron antes que nosotros? ¿En las voces a las que prestamos oídos no resuena el eco de otras voces, ahora mudas? ¿Acaso las mujeres a las que hoy cortejamos no tienen hermanas que ellas no llegaron a conocer? Si es así, entonces, existe una cita secreta entre las generaciones que nos precedieron y la nuestra. Entonces había alguien esperando por nosotros sobre la tierra» $(G S, \mathrm{I} .2,692)$.

Hay quien espera por esta débil fuerza mesiánica, porque ella es la única que puede iluminar, citar una zona de nuestro pasado, que de otro modo quedaría condenada para siempre a la oscuridad y al olvido. Y no podemos fallar a esa cita, pues fallar implicaría el definitivo naufragio de ese pasado que $a$ nosotros se remite, que está esperando por nosotros. El gesto rememorante del pensamiento rasga la costra temporal y se impone, de golpe, en el momento del peligro. De esta manera, un determinado «lugar» del pasado atraviesa fulmíneo el cielo de la historia y, enlazándose con nuestro ahora en una inesperada «constelación», funda un concepto de presente «como ese tiempo de ahora [Jetztzeit], en el cual están diseminadas las astillas del tiempo me- 
siánico» $(G S, \mathrm{I} .2,704)$. El gesto de la rememoración, entonces, rompe la apariencia del continuum del tiempo, donando a nuestro presente la posibilidad de acceder, no al «así fue» de la historia, sino al «revés del tiempo» de los dominadores, a las cifras de esa historia que nunca ha sido escrita, esa historia que pudo ser y no fue. Las imágenes de la historia que el Eingedenken permite recuperar son las imágenes de otro mundo que yace detrás del mundo de la tradición victoriosa.

Es por ello también que la salvación que puede cumplirse a través del Eingedenken es posible «sólo aferrando algo que se está perdiendo irremediablemente». Las coordenadas de esta salvación son el «demasiado temprano» y el «demasiado tarde»; pues la imagen que atraviesa fulmínea y se impone a la humanidad en una época determinada es una imagen que un instante más tarde podría desvanecerse para siempre; una imagen que se disgrega ante cada presente que no esté listo para aferrarla. La tarea del materialista histórico es vigilar, para que ese instante irrepetible que precipita en nuestro presente, trayendo consigo la imagen de un «jamás», no se disuelva sin dejar huellas de sí. Asir esa imagen es retener por un instante el devenir; es más, la constelación que forman pasado y presente constituye esa suspensión: una contracción de los kronoi del tiempo, en cuyo seno se indica al tiempo como salvo, como redimido. Mas tal contracción no puede ser ab-soluta; no es una definitiva detención, sino más bien un «in-star», un improviso entre-tiempo. Escribe Benjamin sobre la interrupción mesiánica, en uno de los Materiales preparatorios para las tesis: "[...] se presenta... como una felicidad fugaz, como el akmé de los griegos: el fiel de la balanza no oscila sino débilmente. No me espero verlo arrancar de vuelta, y menos aún el momento de fijación absoluta, más bien atiendo, en el milagro de esta inmovilidad vacilante, el temblor ligero, imperceptible, que me indica que está vivo» $(G S, I .3,1229)$.

\section{La débil fuerza mesiánica}

Si todo lo que hemos dicho es cierto, el Eingedenken es la figura clave de toda la arquitectura de las Tesis e introduce un leve desplazamiento en la trama conceptual que hemos analizado, sin alterar, sin embargo el carácter unitario de la concepción benjaminiana de la historia y de la temporalidad. Si en el Fragmento la felicidad era sólo la meta del orden de lo profano, cuya flecha seguía una dirección opuesta a la flecha del orden de lo divino, aquí Benjamin escribe explícitamente que en la idea de felicidad vibra la idea de redención. Y el «lugar» en el cual felicidad y redención se conjugan es el instante vacilante y tembloroso de la rememoración: el tiempo del w hahipuk que invierte la relación entre pasado y presente, desencuadernando la linealidad entrópica del tiempo cronológico y transformando lo cumplido en incumplido. Ese tremor ligero indica al tiempo como salvo; sin embargo, no es él 
mismo la salvación del tiempo. Desde este punto de vista, el cuadro conceptual de los años veinte se mantiene intacto: como allí los sabios y los justos, aquí el gesto rememorante evoca e invoca la llegada del Mesías, preparando la tierra para su venida, pero no puede producir tal ad-venimiento. Es por ello que la fuerza de la rememoración es débil: el gesto rememorante puede ser salvífico, mas sólo en la medida en que, resquebrajando el continuum temporal aparente, se traduce en una apertura improvisa, en una grieta que puede ser la puerta a través de la cual entre el Mesías. Y esto queda claro también a partir de la afirmación de Benjamin según la cual la imagen del pasado que relampaguea en el ahora de su cognoscibilidad es una imagen que irrumpe de manera involuntaria: «la historia, en sentido estricto, es una imagen surgida de la rememoración involuntaria, imagen que se le impone súbitamente al sujeto de la historia en el instante del peligro» ${ }^{19}$. Involuntariedad de la imagen del pasado y debilidad mesiánica de la fuerza rememorante activan ahora, en el orden profano de la historia, una tensión que estaba ausente en los textos juveniles.

Debe quedar claro, entonces, que la introducción de la figura del Eingedenken no implica una anulación de la tensión entre mesiánico y Mesías: el tiempo mesiánico no es el tiempo de la parousia, pues el Eingedenken es fuerza «humana, demasiado humana» que, al igual que el ángel de la historia, «quisiera detenerse, despertar a los muertos y recomponer lo destruido», pero está destinada también ella a ser arrastrada hacia el futuro. He aquí la diferencia abismal entre el gesto rememorante de la propuesta benjaminiana y el nietzscheano «así lo quise»: ambos gestos se vuelven hacia el pasado y ambos intentan revocar esa pesada piedra que aplasta y condena al resentimiento. Sin embargo, mientras que el «así lo quise, así lo quiero, así lo querré» de Nietzsche se conjuga dentro de una concepción circular de la temporalidad en la cual no hay espacio para la irrupción de la alteridad, pues la coincidencia anamnésica de voluntad y mundo - de un sí volitivo que, queriéndose, quiere a la totalidad del mundo y, queriendo a la totalidad del mundo, se quiere a sí mismo - es absoluta inmanencia de conciencia y vida, la rememoración benjaminiana es invocación de la alteridad, y es salvífica sólo en la medida en que mantiene este estatuto ${ }^{20}$. En Nietzsche la absoluta circularidad coincide

19 Es evidente que el carácter involuntario de esta imagen, que corre el riesgo de desaparecer y desvanecerse, si no existe un presente capaz de aferrarla, recupera de algún modo la crítica benjaminiana a la idea de la verdad como posesión objetiva, reintroduciendo el concepto de la «muerte de la intención» del texto sobre el Drama barroco.

20 Estamos de acuerdo con Jacob Taubes, cuando sostiene que existe una distancia enorme entre la concepción benjaminiana de la historia y la concepción nietscheana de la misma; Taubes, Jacob (2006), «Walter Benjamin: Geschichtsphilosophische Thesen (Seminar - Wintersemester 1984'85)»; en Der Preis des Messianismus, op. cit., pp. 67-92. Es cierto, como dice Marramao, criticando la posición taubesiana, que Benjamin había leído con gran interés a Nietzsche y que su polémica y hostilidad estaban dirigidas casi exclusivamente a Heidegger; pero esto no quita la diferencia radical de actitud y temperamento filosófico de ambos pensa- 
con el máximo de voluntad y esta consunción recíproca de temporalidad y voluntad es entumecimiento del devenir en un idéntico que retorna incesantemente igual a sí mismo; absoluta estaticidad. En Benjamin, la débil fuerza mesiánica ni detiene ni consuma la historia, pues se cumple como un «pequeño salto en medio de la catástrofe continua».

En las Tesis Benjamin parece dejar de lado la idea de una detención absoluta del tiempo y se concentra en cambio sobre estas suspensiones vacilantes del tiempo que el Eingedenken permite: Jetztzeit que mantiene en sí unidos, pero como infinita diferencia, histórico y eterno. En este sentido, a diferencia de lo que ocurría en el Fragmento, cuando Benjamin descartaba cualquier forma de analogía débil, aquí la Jetztzeit, como constelación prismática, parece constituirse como una suerte de modelo de lo mesiánico en la historia ${ }^{21}$. Si en el Fragmento el cumplimiento de la política mundial tenía que llamarse «nihilismo», si la historia tenía que «hacerse desierto» para prepararse a la llegada arrasadora del Reino, aquí Benjamin ve en la débil fuerza mesiánica que nos ha sido concedida la posibilidad de encender esa chispa capaz de iluminar y por ello «salvar», si bien sólo por un instante, todo el dolor que el «matadero de la historia» lleva consigo. Sin embargo, otra vez, la Jetztzeit no es captura del eterno presente del Reino. El hombre no puede remontar el exilio, recomponer lo destruido. Puede sólo, con su gesto rememorante, hacer llegar a su corazón las astillas en las cuales resuenan los gritos entrañables de lo viviente y, al mismo tiempo, el eco lejano del Reino de Dios que se acerca con pasos sigilosos.

dores; y tampoco se puede negar que la filosofía benjaminiana rechaza toda forma de inmanentismo; Marramao, Giacomo (2005), «Messianismo senza attesa. Sulla teologia politica di Walter Benjamin», en Aut-Aut, op. cit., pp. 119-134. Sobre el concepto de historia en Benjamin y en Nietzsche véase también Mazzarella, Eugenio (1983), «L'angelo e l'attesa. Allegoria e simbolo nelle "Tesi di filosofia della storia" di Walter Benjamin», en Id., Nietzsche e la storia. Storicità e ontologia della vita, Napoli, Guida, pp. 168-187. Mazzarella pone en evidencia una oscilación en el concepto de débil fuerza mesiánica de las Tesis, que llevavía Benjamin a un abandono de la debilidad de tal fuerza y a una intensificación de la misma en la dirección del concepto nietzscheano de «voluntad de potencia»: «La fuerza mesiánica de los agentes históricos tiende, de hecho a pretender para sí un quantum de fuerza plástica capaz de reducir a un valor igual a cero la necesidad de olvidar: en otros términos, el horizonte a partir del cual se instituye la acción histórica queda colocado en el infinito, recuperando para sí la totalidad del acaecer histórico - la redención total y definitiva del pasado que las tesis reclaman necesita, de hecho, en virtud de su misma lógica, una anamnesis total» (p. 171). A partir de lo que hemos dicho en el texto, queda claro que no estamos de acuerdo con esta lectura, aunque es cierto que la insistencia benjaminiana en la acción revolucionaria del materialista histórico crea una cierta ambigüedad y hace pensar en una intensificación radical de tal fuerza mesiánica.

21 Es probable que la urgencia de los eventos políticos que estaban devastando Europa en aquellos años haya llevado a Benjamin a acentuar el carácter anticipatorio de la espera mesiánica que a través de la fuerza de la rememoración es capaz de hacer disparar la acción revolucionaria. 


\section{BIBLIOGRAFÍA}

Benjamin, Walter (1974-1989): Gesammelte Schriften, 7 Bde, Frankfurt am Main, Suhrkamp Verlag.

BonolA, Giorgio (2000): «Antipolitica messianica. La giustizia di Dio come critica del diritto e del "politico" nel filosofare comune di G. Scholem e W. Benjamin (1916-1920)», en Fenomenologia e società: Walter Benjamin: pensare la storia, n. 2, año XXIII, pp. 3-36.

De Michele, Girolamo, «L'impercettibile tremolio della felicità. Tempo e dialettica in stato di arresto», en Fenomenologia e società: Walter Benjamin: pensare la storia, n. 2, año XXIII, pp. 58-71.

Desideri, Fabrizio (2001): «Teologia dell'inferno. Walter Benjamin e il feticismo moderno»; en Stefano Mistura (ed.), Figure del fetichismo, Torino, Einaudi, pp. $175-196$.

FOLKERS, Horst (1979): «Zum Begriff der Gewalt bei Kant und Benjamin»; en Gunter Figal y Horst Folkers (Hrsg.), Zur Theorie der Gewalt und Gewaltlosigkeit bei Walter Benjamin, Heidelberg, Fest, pp. 25-57.

Koselleck, Reinhart (1979): Vergangene Zukunft. Zur Semantik Geschichtlicher Zeiten, Frankfurt am Main, Suhrkamp Verlag.

MAZZARELlA, Eugenio (1983): «L'angelo e l'attesa. Allegoria e simbolo nelle "Tesi di filosofia della storia" di Walter Benjamin»; en Id., Nietzsche e la storia. Storicità e ontologia della vita, Napoli, Guida, pp. 168-187.

MArramaO, Giacomo (2005): «Messianismo senza attesa. Sulla teologia politica di Walter Benjamin», en Aut-Aut, cit., pp. 119-134.

Marramao, Giacomo (1995): Potere e secolarizzazione. Le categorie del tempo, Roma, Editori Riuniti.

Scholem, Gershom (1995): Tagebücher nebst Aufsätze und Entwürfe bis 1923, I. Halbband 1913-1917 (hrsg. von K. GRÜNDER und F. NIEWÖHNER), Frankfurt am Main, Jüdischer Verlag.

Scholem, Gershom (1971): The Messianic Idea of Judaism and Other Essays on Jewish Spirituality, New York, Schocken Books.

Scholem, Gerschom (1995): 95 Thesen über Judentum und Zionismus; en Id., Zwischen den Disziplinen, Frankfurt am Main, Suhrkamp Verlag, pp. 287-95.

SzONDI, Peter (1978): Hoffnung im Vergangenen. W.B. und die Suche nach der vorlorenen Zeit, en Id., Schriften II, Frankfurt am Main, Suhrkamp Verlag.

TAuBES, Jacob (2006): «Walter Benjamin: Geschichtsphilosophische Thesen (Seminar - Wintersemester 1984'85)»; en Id., Der Preis des Messianismus, (hrsg. von E. Stimilli), Würzburg, Königshausen \& Neumann, pp. 67-92.

TAubes, Jacob (1993): Die politische Theologie des Paulus, München, Fink Verlag.

TomBA, Massimiliano (2006): La «vera politica». Kant e Benjamin: la possibilità della giustizia, Macerata, Quodlibet. 